DOI: 10.5216/cab.v13i3.17511

\title{
CARACTERÍSTICAS DE CARCAÇA E BIOMETRIA TESTICULAR DE MACHOS BOVINOS SUPERJOVENS NÃO CASTRADOS DE DIFERENTES GRUPOS GENÉTICOS
}

\author{
FABIANO NUNES VAZ ${ }^{1}$, JORGE LUIS CARVALHO FLORES ${ }^{2}$, RICARDO ZAMBARDA VAZ ${ }^{3}$, LEONIR LUIZ \\ PASCOAL ${ }^{1}$, MOZER MANETTI DE ÁVILA ${ }^{4}$ \\ ${ }^{1}$ Professores Doutores da Universidade Federal de Santa Maria, Santa Maria, RS, Brasil. fabianonunesvaz@gmail.com \\ ${ }^{2}$ Zootecnista do Instituto Federal Farroupilha, São Vicente do Sul, RS, Brasil \\ ${ }^{3}$ Professor Doutor na Universidade Federal de Pelotas, Pelotas, RS, Brasil \\ ${ }^{4}$ Graduando de Zootecnia da Universidade Federal do Pampa, Dom Pedrito, RS, Brasil.
}

O objetivo deste trabalho foi avaliar as características de carcaça e a biometria testicular de machos não castrados superjovens das raças Hereford $(\mathrm{H}), 3 / 4 \mathrm{H} 1 / 4$ Nelore (3/4HN), 5/8H 3/8 Nelore (5/8HN) e 3/4 Charolês $1 / 4$ Nelore $(3 / 4 \mathrm{CN})$, abatidos aos quatorze meses de idade. Não houve diferenças estatísticas entre os grupos genéticos para pesos de fazenda, de carcaça e rendimentos de carcaça. A percentagem de serrote foi maior nos animais 3/4CN em relação aos outros genótipos. A percentagem de ponta de agulha foi maior nos $5 / 8 \mathrm{HN}$ em relação aos 3/4HN e 3/4CN. A área de Longissimus dorsi foi maior nos animais $3 / 4 \mathrm{CN}\left(71,5 \mathrm{~cm}^{2}\right)$ em relação aos
Hereford $\left(63,5 \mathrm{~cm}^{2}\right)$. Animais Hereford também apresentaram menor comprimento de membro posterior do que todos os demais grupos. Os machos 3/4CN apresentaram menor $(2,6 \mathrm{~mm})$ espessura de gordura subcutânea do que os Hereford $(5,0 \mathrm{~mm}), 5 / 8 \mathrm{HN}(4,1$ $\mathrm{mm})$ e $3 / 4 \mathrm{HN} \quad(4,1 \mathrm{~mm})$. Concluiu-se que as características relacionadas à musculosidade, como a conformação e o rendimento de serrote foram melhores no genótipo mestiço Charolês, enquanto as características relacionadas à deposição de gordura, como espessura de gordura e rendimento de ponta de agulha, foram melhores nos animais Hereford e mestiços.

PALAVRAS-CHAVE: confinamento; cruzamento; Hereford; Nelore; rendimentos.

\section{CARCASS CHARACTERISTICS AND TESTICULAR BIOMETRY OF YOUNG NON- CASTRATED MALES OF DIFFERENT GENETIC GROUPS}

\section{ABSTRACT}

The objective of this work was to evaluate carcass characteristics and testicular biometry of non-castrated Hereford $(\mathrm{H}), 3 / 4 \mathrm{H} 1 / 4$ Nellore $(\mathrm{N}), 5 / 8 \mathrm{H} 3 / 8 \mathrm{~N}$ and $3 / 4$ Charolais (C) $1 / 4 \mathrm{~N}$ males, slaughtered at fourteen months of age. No statistical difference occurred among genetic groups for final and carcasses weights and dressing percentages. The sawcut yield was higher in $3 / 4 \mathrm{CN}$ than other genotypes. Ribcut yield was higher for $5 / 8 \mathrm{HN}$ in relation to $3 / 4 \mathrm{HN}$ and $3 / 4 \mathrm{CN}$. Longissimus dorsi area was higher for $3 / 4 \mathrm{CN}\left(71.5 \mathrm{~cm}^{2}\right)$ animals in relation to Hereford $\left(63.5 \mathrm{~cm}^{2}\right)$. Hereford animals also showed lower leg length than all other groups. The $3 / 4 \mathrm{CN}$ males showed lower $(2.6 \mathrm{~mm})$ subcutaneous fat thickness than Hereford $(5.0 \mathrm{~mm}), 5 / 8 \mathrm{HN}(4.1 \mathrm{~mm})$ and $3 / 4 \mathrm{HN}(4.1 \mathrm{~mm})$ ones. In conclusion, all genetic groups get compatible carcass characteristics for young cattle market. Besides, muscular development related characteristics, such as conformation and sawcut yield, were better in Charolais crossbred genotype, while characteristics related to fat deposition, such as fat thickness and ribcut yield, were better in Hereford and crossbred Hereford genotypes.

KEYWORDS: crossbred; feedlot; Hereford; Nellore; yield. 


\section{INTRODUÇÃO}

As variações climáticas que ocorrem de Norte a Sul do Brasil estabeleceram diferentes sistemas produtivos pecuários do maior rebanho comercial do mundo. Nesse contexto, os produtores rurais têm dúvidas sobre quais genótipos são mais apropriados às finalidades estabelecidas em cada sistema produtivo das empresas rurais brasileiras (SANTOS et al., 2002).

A complementaridade das raças é a base do sucesso dos cruzamentos e vários estudos têm mostrado que o melhor resultado na formação das raças sintéticas é a combinação de zebu com raças europeias (KOGER, 1980). Entre as zebuínas, a raça Nelore é a de maior participação no rebanho nacional, seja para a produção de animais definidos ou para a produção de mestiços, resultado do cruzamento com bovinos Bos taurus taurus. Segundo TORAL et al. (2011), uma opção para acelerar a produção de carne bovina nos trópicos é a utilização de raças de origem europeia sobre a base Nelore existente no rebanho brasileiro. Para os autores, as raças europeias já passaram por longo processo de melhoramento genético e, portanto, são mais produtivas.

Atualmente, a raça Hereford é considerada, em todo o mundo, um dos genótipos de corte mais precoce entre as raças que possuem rebanho expressivo. Além disso, é reconhecida pela qualidade da carne, que possui acentuado marmoreio e boa maciez, se comparada a outras raças de maior porte (SHERBECK et al., 1995). Pela sua precocidade, a raça se constitui em um genótipo indicado para sistemas de produção de ciclo curto (TORAL et al., 2011). Esses sistemas geram carne de qualidade acentuada, em razão disso, melhor valorizada, gerando melhor remuneração para toda a cadeia produtiva.

Por outro lado, a raça Charolês está presente em grande parte dos cruzamentos da região Sul, mas também é expressiva no restante do Brasil. Isso se deve pela sua adaptabilidade e pelo porte da raça que resulta em bezerros mais pesados ao desmame e ao abate e carcaças de boa conformação e peso (PEROTTO et al., 2000).

A literatura tem mostrado que a pesquisa de animais superjovens pode ser justificada por três motivos principais: i) o abate de bovinos com um ano de idade é uma boa opção para criadores de raças precoces, como é o caso do Hereford e seus mestiços (SHERBECK et al., 1995); ii) sistemas produtivos de ciclo curto são biológica e economicamente mais eficientes (IGARASI et al.,
2008); e iii) quanto mais jovem for a idade ao abate, melhor a qualidade da carne (LAWRIE, 2005).

O uso de animais não castrados também se justifica por três razões principais: i) animais não castrados têm maior velocidade de crescimento que animais castrados e que as fêmeas, em função do efeito anabólico dos hormônios masculinos (ÍTAVO et al., 2008); ii) em sistemas de ciclo curto, o processo de castração e o estresse decorrente podem representar um pequeno período durante o qual os animais perdem peso (BAKER, 2008); e iii) animais inteiros abatidos em idade jovem não possuem carcaças com menor valor comercial, haja vista que o dimorfismo sexual é pouco pronunciado até um ano de idade (BERG \& BUTTERFIELD, 1976). Nesse sentido, este trabalho teve por objetivo avaliar as características de carcaça e a biometria testicular de machos não castrados, das raças Hereford (H), 3/4 H $1 / 4$ Nelore $(3 / 4 \mathrm{HN}), 5 / 8$ H $3 / 8$ Nelore $(5 / 8 \mathrm{HN})$ e $3 / 4$ Charolês $1 / 4$ Nelore $(3 / 4 \mathrm{CN})$, confinados e abatidos aos quatorze meses de idade.

\section{MATERIAL E MÉTODOS}

Este trabalho foi realizado no Setor de Bovinocultura de Corte do Departamento de Zootecnia da Universidade Federal de Santa Maria, Rio Grande do Sul, no período de junho a dezembro de 1995, utilizando-se 32 bezerros machos inteiros, desmamados aos sete meses de idade, nascidos e criados sob as mesmas condições sanitárias, de manejo e de alimentação ao pé da vaca, sem o uso de creep feeding. No início do trabalho os animais apresentavam peso médio de $195 \mathrm{~kg}$, pertencentes a quatro grupos genéticos, sendo oito da raça Hereford $(\mathrm{H})$, oito $3 / 4 \mathrm{H} 1 / 4$ Nelore $(\mathrm{N})$, oito $5 / 8 \mathrm{H} 3 / 8 \mathrm{~N}$ e oito $3 / 4$ Charolês $(\mathrm{C})$ $1 / 4 \mathrm{~N}$, oriundos de propriedade particular.

$\mathrm{O}$ experimento foi conduzido em confinamento, usando-se silagem de milho como volumoso, sendo que a relação volumoso/concentrado variou de $70 / 30$ no $1^{\circ}$ período até $40 / 60$ no $7^{\circ}$ período, apresentando relação média de 56,4/43,6 (base da matéria seca MS). O concentrado apresentava, na média, 46,8\% de farelo de soja, $51,0 \%$ de milho em grão triturado, $1,0 \%$ de sal comum e $1,2 \%$ de calcário calcítico. Nos quatro primeiros períodos de 28 dias a dieta apresentou $16,1 \%$ de proteína bruta, a partir do $5^{\circ}$ período foi recalculada e apresentou $12,8 \%$ de proteína bruta. A dieta oferecida possuía 3,16 $\mathrm{Mcal} / \mathrm{kg}$ de energia digestível, 2,60 Mcal $/ \mathrm{kg}$ de 
energia metabolizável, 1,69 Mcal/kg de energia líquida de manutenção e $1,08 \mathrm{Mcal} / \mathrm{kg}$ de energia líquida para ganho de peso estimado em $1,0 \mathrm{~kg}$ por dia (NRC, 1996).

O período de adaptação dos animais à dieta e instalações foi de 14 dias. A alimentação era fornecida à vontade duas vezes ao dia Diariamente, pela manhã antes da pesagem da dieta, eram retiradas as sobras do dia anterior e registradas em uma planilha de campo para se obter o consumo do dia anterior.

As pesagens dos animais ocorreram no início do período experimental e, depois, a cada 28 dias, com exceção do $3^{\circ}$ e $7^{\circ}$ período, quando foram realizadas com 27 e 21 dias, respectivamente, perfazendo um período total de 188 dias. Antecedendo as pesagens, os animais eram submetidos a jejum de sólidos de 14 horas. Esse mesmo procedimento ocorreu antes dos animais serem enviados ao abatedouro comercial, obtendo-se o peso de fazenda dos animais.

No momento da pesagem dos animais, antes do embarque para o abatedouro, foi medido o perímetro escrotal, com auxílio de fita métrica.

Por ocasião do abate as duas meias carcaças foram identificadas com fichas metálicas numeradas. O par de testículos de cada animal foi coletado logo após a sua remoção na linha de abate, seguindo-se a separação da porção glandular e imediata pesagem dessa porção.

Ao final da linha de abate, as duas meias carcaças foram pesadas, antes da lavagem, para obtenção do peso de carcaça quente. Depois de lavadas, as mesmas foram levadas para câmara fria, onde permaneceram por 24 horas, sob temperatura de 1 grau centígrado.

Depois de resfriadas, as carcaças foram novamente pesadas, obtendo-se o peso de carcaça fria dos animais. A diferença de peso entre as duas medidas, expressa em percentagem do peso de carcaça quente, representou a quebra de peso durante o resfriamento das carcaças. As medidas de comprimentos de carcaça, de membro posterior e de membro anterior, a espessura de coxão e o perímetro do membro anterior foram realizadas na carcaça direita, depois do resfriamento.

A meia carcaça esquerda foi dividida nos três cortes comerciais: serrote, dianteiro e ponta de agulha, segundo o método usado pelos abatedouros frigoríficos. O serrote ou traseiro especial compreende a região posterior (caudal) da carcaça. O corte é separado do dianteiro e da ponta de agulha entre a $5^{a}$ e $6^{a}$ costela, a $\pm 22 \mathrm{~cm}$ da coluna vertebral, permanecendo com oito costelas.

O dianteiro compreende a região anterior (cranial) da carcaça, separado do traseiro e da ponta de agulha entre a $5^{a}$ e $6^{a}$ costelas, permanecendo com a $5^{a}$ costela. A ponta de agulha, ou costilhar, compreende a região lateral e ventral da carcaça, formada pelas oito costelas do traseiro e o vazio.

A espessura de gordura subcutânea foi medida em mm, após o resfriamento das carcaças, medindo a gordura que recobre o músculo Longissimus dorsi, a partir do corte realizado entre a $12^{a}$ e $13^{a}$ costela, sendo utilizada a média de duas leituras. A área de lombo foi medida no músculo Longissimus dorsi, exposto por um corte transversal na carcaça entre a $12^{a}$ e $13^{a}$ costela.

Também após o resfriamento, a conformação de carcaças foi realizada visualizando-se as duas metades da carcaça, subjetivamente, por meio de uma escala de pontos indicados por MÜLLER (1987), procurando-se evitar que a gordura de cobertura interferisse na avaliação. Já para a avaliação da maturidade fisiológica da carcaça, foi usada uma escala de quinze pontos descrita por MÜLLER (1987). Essa medida foi realizada através da avaliação da calcificação das cartilagens do processo espinhoso das vértebras torácicas, lombares e entre as vértebras sacrais. Para a determinação da composição física da carcaça, foi retirada uma secção incluindo a $9^{\mathrm{a}}, 10^{\mathrm{a}}$ e $11^{\mathrm{a}}$ costelas, segundo a metodologia proposta por HANKINS \& HOWE (1946).

O delineamento experimental adotado foi o inteiramente casualizado, com quatro tratamentos e oito repetições, em que cada animal constituiu uma unidade experimental. Foram realizadas as análises de variância, aplicando-se o teste $\mathrm{F}$ e, quando as médias mostraram diferença estatística $(\mathrm{P}<0,05)$, foram comparadas pelo teste de Tukey.

\section{RESULTADOS E DISCUSSÃO}

A Tabela 1 apresenta os pesos e os rendimentos de carcaça e quebra durante o resfriamento. Não foi observada diferença entre os grupos genéticos para o peso de fazenda dos animais, bem como para o peso de carcaça quente e o peso de carcaça fria $(\mathrm{P}>0,05)$. 
Tabela 1 - Pesos de fazenda, de carcaça quente e fria, rendimentos de carcaça quente e fria e quebra no resfriamento da carcaça de bovinos não castrados de diferentes grupos genéticos, abatidos aos quatorze meses

\begin{tabular}{lllllll}
\hline Características & $\mathrm{H}^{\mathrm{a}}$ & $3 / 4 \mathrm{HN}^{\mathrm{b}}$ & $5 / 8 \mathrm{HN}^{\mathrm{c}}$ & $3 / 4 \mathrm{CN}^{\mathrm{d}}$ & $\mathrm{CV}^{\mathrm{e}}, \%$ & $\mathrm{P}^{\mathrm{f}}$ \\
\hline Peso de fazenda, $\mathrm{kg}$ & 440 & 436 & 453 & 451 & 6,11 & 0,63 \\
Peso de carcaça quente, $\mathrm{kg}$ & 236 & 240 & 251 & 242 & 6,63 & 0,32 \\
Peso de carcaça fria, kg & 232 & 233 & 242 & 242 & 6,14 & 0,31 \\
Rendimento de carcaça quente, $\%$ & 53,6 & 55,1 & 55,4 & 54,6 & 3,64 & 0,28 \\
Rendimento de carcaça fria, \% & 52,7 & 54,1 & 54,3 & 53,8 & 3,67 & 0,32 \\
Quebra ao resfriamento, \% & 1,79 & 1,28 & 1,98 & 1,50 & 0,47 & 0,62 \\
\hline${ }^{a}$ Hereford, ${ }^{\mathrm{b}}$ 3/4 Hereford $1 / 4$ Nelore, ${ }^{\mathrm{c}}$ 5/8 Hereford $3 / 8$ Nelore, ${ }^{\mathrm{d}}$ 3/4 Charolês $1 / 4$ Nelore, ${ }^{\mathrm{e}}$ coeficiente de variação, ${ }^{\mathrm{f}}$ probabilidade.
\end{tabular}

As similaridades nos pesos de carcaça quente e de carcaça fria observadas neste trabalho indicam que os efeitos de heterozigose dos animais mestiços não foram pronunciados de forma a resultar em maior peso de carcaça em relação ao genótipo Hereford puro. Tal comportamento pode ser em razão de todos os genótipos envolvidos no experimento se tratarem de raças de corte, diferente dos resultados de VAZ et al. (2002), que verificaram peso de abate de 379,9 e $371,3 \mathrm{~kg}$, respectivamente, para Hereford e $5 / 8 \mathrm{HN}$, enquanto os animais $1 / 2$ Jersey 1/2 Hereford mostraram valor inferior, 346,6 $\mathrm{kg}$, em novilhos abatidos também aos quatorze meses de idade.

Os valores de peso de abate e pesos de carcaça dos animais dos diferentes genótipos se constituíam em uma das grandes questões a serem estudadas no presente trabalho, buscando-se compreender o efeito do cruzamento com Nelore sobre a alteração de peso em relação aos Hereford definidos. A similaridade no peso de abate e nos pesos de carcaça dos animais se refletiu em rendimentos de carcaça quente e fria também similares entre os genótipos $(\mathrm{P}>0,05)$. Os valores médios para essas características foram de 54,7 e $53,7 \%$, respectivamente. A literatura cita que animais mestiços zebuínos devem apresentar maior rendimento de carcaça que raças britânicas (BIDNER et al., 2002). PACHECO et al. (2005) relataram rendimento de carcaça quente de $57,5 \%$ nos novilhos com maior percentagem de sangue zebu contra 54,1\% nos novilhos com maior percentagem de raça continental. $\mathrm{O}$ rendimento de carcaça fria também foi maior nos primeiros $(54,8$ contra $52,6 \%)$.

Mesmo inferior ao rendimento relatado por PACHECO et al. (2005), o valor médio de rendimento de carcaça quente $54,7 \%$ é considerado elevado se comparado com as médias verificadas em outros trabalhos que pesquisaram animais superjovens, porém castrados (PACHECO et al., 2005), efeito do dimorfismo sexual do animal inteiro, que, ao desenvolver maior musculatura, resulta em maior rendimento de carcaça que o macho castrado (PURCHAS et al., 2002). SAMPAIO et al. (1998) também observaram rendimento alto $(55,1 \%)$ em bovinos jovens não castrados mestiços Canchim. Além disso, é importante salientar que as comparações entre rendimentos de carcaça medidos em diferentes experimentos pode ser resultado de variação no método de recorte dos excessos de gordura da carcaça e da gordura interna, que variam de frigorífico para frigorífico e são subjetivos nos abatedouros experimentais.

No presente trabalho, as quebras ao resfriamento da carcaça variaram de 1,28 a 1,98\%, sem diferença estatística entre os quatro genótipos. As quebras ao resfriamento verificadas por PACHECO et al. (2005) $(4,63 \%$ nos $5 / 8 \mathrm{~N} 3 / 8 \mathrm{C}$ e $2,74 \%$ nos $5 / 8 \mathrm{C} 3 / 8 \mathrm{~N}$ ) e por VAZ et al. (2002) $(2,70 \%$ para Hereford e $2,37 \%$ para $5 / 8 \mathrm{HN})$ não foram estatisticamente diferentes entre os genótipos e ambas, na média, foram inferiores às observadas no presente estudo. Essas diferenças nas quebras durante o resfriamento da carcaça poderiam ser resultado de diferenças na cobertura de gordura sobre as carcaças ou alterações no $\mathrm{pH}$ muscular (LAWRIE, 2005), decorrentes de variações durante o manejo pré-abate, podendo ser prejudicado em função dos animais mestiços Nelore serem mais susceptíveis a maior estresse pré-abate em relação aos Hereford. No entanto, o fato de os animais permanecerem em confinamento por quase sete meses reduz a susceptibilidade desses ao estresse pré-abate, em função do constante contato com pessoas e espaços reduzidos no local do confinamento, condições similares às encontradas no abatedouro.

$\mathrm{Na}$ Tabela 2, observa-se que a espessura de gordura subcutânea da carcaça foi inferior $(\mathrm{P}<0,05)$ nos animais mestiços Charolês em relação aos demais, que não diferiram entre si. Pesquisando bovinos Charolês em comparação com bovinos de 
raça britânica, no caso Aberdeen Angus, BARBER et al. (1981) afirmam que a raça Charolês atinge peso maduro em idade mais avançada, com isso, em pesos reduzidos, deve-se esperar maior espessura de gordura sobre as carcaças de animais de raças britânicas.

Tabela 2 - Espessura de gordura subcutânea, área de Longissimus dorsi absoluta e ajustada para peso de carcaça quente, conformação e medidas métricas da carcaça de bovinos não castrados de diferentes grupos genéticos, abatidos aos quatorze meses

\begin{tabular}{lllllll}
\hline Características & $\mathrm{H}^{\mathrm{a}}$ & $3 / 4 \mathrm{HN}^{\mathrm{b}}$ & $5 / 8 \mathrm{HN}^{\mathrm{c}}$ & $3 / 4 \mathrm{CN}^{\mathrm{d}}$ & $\mathrm{CV}^{\mathrm{e}}, \%$ & $\mathrm{P}^{\mathrm{f}}$ \\
\hline Espessura de gordura, mm & $5,0^{\mathrm{g}}$ & $4,1^{\mathrm{g}}$ & $4,1^{\mathrm{g}}$ & $2,6^{\mathrm{h}}$ & 35,40 & 0,03 \\
Área de Longissimus dorsi, cm $\mathrm{cm}^{2}$ & $63,5^{\mathrm{h}}$ & $67,8^{\mathrm{gh}}$ & $69,4^{\mathrm{gh}}$ & $71,5^{\mathrm{g}}$ & 9,30 & 0,04 \\
Área de Longissimus dorsi, cm $^{2} / 100 \mathrm{~kg}$ & 27,4 & 29,3 & 28,1 & 29,5 & 9,09 & 0,41 \\
Conformação, pontos $^{\mathrm{e}}$ & $12,1^{\mathrm{gh}}$ & $12,0^{\mathrm{h}}$ & $11,5^{\mathrm{h}}$ & $13,3^{\mathrm{g}}$ & 9,41 & 0,04 \\
Comprimento de carcaça, cm $_{\text {Comprimento de membro anterior, cm }}$ & 124 & 121 & 124 & 126 & 11,02 & 0,09 \\
Comprimento de membro posterior, cm & $64,4^{\mathrm{h}}$ & $38,6^{\mathrm{gh}}$ & $39,3^{\mathrm{g}}$ & $39,9^{\mathrm{g}}$ & 7,05 & 0,04 \\
Espessura de coxão, cm & $66,6^{\mathrm{g}}$ & $67,8^{\mathrm{g}}$ & $67,6^{\mathrm{g}}$ & 11,99 & 0,02 \\
Perímetro de membro anterior, cm $^{\mathrm{a}}$ & 23,9 & 24,6 & 25,0 & 25,8 & 34,1 & 0,33 \\
\hline
\end{tabular}

${ }^{\mathrm{a}}$ Hereford, ${ }^{\mathrm{b}} 3 / 4$ Hereford $1 / 4$ Nelore, ${ }^{\mathrm{c}} 5 / 8$ Hereford $3 / 8$ Nelore, ${ }^{\mathrm{d}} 3 / 4$ Charolês $1 / 4$ Nelore; ${ }^{\mathrm{e}}$ escala de 1 a 18 pontos, sendo $10=$ boa menos, 11 = boa típica e 12 = boa mais, ${ }^{\mathrm{e}}$ coeficiente de variação, ${ }^{\mathrm{f}}$ probabilidade, ${ }^{\mathrm{g}, \mathrm{h}}$ na linha, média seguidas por letras diferem significativamente entre os grupos genéticos, pelo teste $t$ ao nível de $5 \%$.

Poderia ser esperada, ainda, diferença entre a espessura de gordura da carcaça dos animais mestiços Hereford x Nelore das heterozigoses 50\% $(3 / 4 \mathrm{HN})$ e $62 \%(5 / 8 \mathrm{HN})$, o que não foi observado (Tabela 2; P>0,05). Esperava-se isso, pois VAZ \& RESTLE (2001) afirmam que as medidas relacionadas à deposição de gordura da carcaça são as características que possuem maior efeito de heterose. Similaridade entre genótipos puros e mestiços que envolvem as raças Hereford e Nelore foram citadas por VAZ et al. (2002), quando observaram 6,25 e 6,74 mm de espessura de gordura, respectivamente, para os genótipos Hereford e $5 / 8 \mathrm{HN}$, em novilhos terminados em confinamento desde os sete meses e abatidos aos quatorze meses de idade.

No presente trabalho, a conformação de carcaças foi maior $(\mathrm{P}<0,05)$ nos $3 / 4 \mathrm{CN}$ em relação aos mestiços Hereford x Nelore, mas não diferiram do Hereford puro (Tabela 2). As raças continentais, como é o caso da Charolês, são caracterizadas por carcaças com melhor conformação em relação às britânicas, no caso a Hereford; no entanto, no presente trabalho, somente quando o Nelore foi incluído no genótipo, a conformação de carcaças decresceu. Os animais Hereford e mestiços Hereford x Nelore não diferiram entre si nessa característica. A conformação verificada por VAZ et al. (2002) foi similar, assim como as áreas absolutas de Longissimus dorsi, que foram de 55,5 e $57,0 \mathrm{~cm}^{2}$, respectivamente, para Hereford e 5/8HN. Ajustada para $100 \mathrm{~kg}$ de carcaça, os valores passaram a ser 28,4 e $29,0 \mathrm{~cm}^{2}$, citados na mesma ordem.

No presente trabalho, assim como a conformação, a área de Longissimus dorsi absoluta, que também é um indicativo da musculosidade da carcaça (BERG \& BUTTERFIELD, 1976), foi superior nos $3 / 4 \mathrm{CN}$, dessa vez em relação aos machos Hereford, não diferindo dos mestiços $3 / 4$ e 5/8 (Tabela 2). A similaridade entre cruzados Charolês e Hereford indica que a heterozigose dos últimos compensou parte da maior aptidão das raças continentais para desenvolver a musculosidade na carcaça.

No entanto, ainda na Tabela 2, observa-se que, ao ajustar a característica para $100 \mathrm{~kg}$ de carcaça, a diferença deixou de existir $(\mathrm{P}>0,05)$, embora numericamente o cruzado $3 / 4 \mathrm{CN}$ tenha mostrado área $2,1 \mathrm{~cm}^{2}$ maior que o Hereford puro. A partir desses resultados, pode-se inferir que o peso de carcaça afeta a área de Longissimus dorsi e, nessa medida, a heterozigose dos animais mestiços pode reduzir a diferença de musculosidade entre as raças britânicas como a Hereford e continentais como a Charolês (PEROTTO et al., 2000).

Essa afirmação se consolida quando se observa que, ao comparar os animais $3 / 4 \mathrm{CN}$ e $3 / 4 \mathrm{HN}$ entre si, verifica-se que não houve diferença entre os grupos para nenhuma das características métricas de mensuração da carcaça (Tabela 2). Também os $5 / 8 \mathrm{HN}$ foram similares aos 3/4HN $(\mathrm{P}>0,05)$. O comprimento de carcaça, espessura de coxão e 
perímetro de membro anterior não diferiram entre os grupos genéticos $(\mathrm{P}>0,05)$. Ainda em relação às medidas métricas da carcaça, constata-se que os animais Hereford apresentaram menor comprimento de membro anterior do que os mestiços $5 / 8 \mathrm{HN}$ e $3 / 4 \mathrm{CN}$ e menor comprimento de membro posterior do que os demais grupos (Tabela 2).

Os mestiços Nelore tendem a ter membros mais compridos que as raças europeias definidas, resultado da heterose individual para as características de desenvolvimento corporal (ARANGO et al., 2004). Esse comportamento pode ser maximizado quando o genótipo mestiço zebu envolver outra raça como a Charolês, uma raça continental de maior porte que a Hereford. Ainda na Tabela 2, pode-se verificar que, se forem considerados somente os animais Hereford e seus mestiços com Nelore, os comprimentos de perna e de braço aumentaram com o incremento da proporção de Nelore.

Se considerados apenas os machos Hereford e Hereford $\mathrm{x}$ Nelore, observa-se que a área de
Longissimus dorsi em valores absolutos e ajustado para peso de carcaça fria não foi afetada pelo cruzamento. SHERBECK et al. (1995) afirmam que animais cruzados Brahman apresentam menor área de longissimus dorsi do que novilhos de raças britânicas.

A Tabela 3 mostra os dados referentes aos pesos dos cortes comerciais das carcaças dos animais dos diferentes genótipos, constatando-se que houve similaridade entre os genótipos para os pesos dos três cortes comerciais. A similaridade entre os pesos dos cortes decorre da similaridade nos pesos de carcaça dos animais (Tabela 1). Os resultados indicaram não existir efeito das raças Nelore, Hereford e Charolês para essa característica. OLIVEIRA et al. (2009) observaram maior peso de dianteiro em tourinhos Nelore em relação a tourinhos Canchim, diferença que também se constatou no rendimento percentual desse corte, que foi de 39,3 e $38,1 \%$, respectivamente. Para os autores, tal diferença foi devido à presença do cupim no corte dianteiro das carcaças de animais Nelore.

Tabela 3 - Peso dos cortes comerciais (serrote, ponta de agulha e dianteiro) de bovinos não castrados de diferentes grupos genéticos, abatidos aos quatorze meses

\begin{tabular}{lllllll}
\hline Características & $\mathrm{H}^{\mathrm{a}}$ & $3 / 4 \mathrm{HN}^{\mathrm{b}}$ & $5 / 8 \mathrm{HN}^{\mathrm{c}}$ & $3 / 4 \mathrm{CN}^{\mathrm{d}}$ & $\mathrm{CV}, \%^{\mathrm{e}}$ & $\mathrm{P}^{\mathrm{f}}$ \\
\hline Serrote, kg & 53,7 & 54,4 & 55,1 & 58,3 & 11,02 & 0,29 \\
Ponta de agulha, kg & 18,9 & 18,3 & 20,3 & 17,0 & 14,51 & 0,37 \\
Dianteiro, kg & 43,2 & 43,8 & 46,4 & 45,9 & 9,99 & 0,22 \\
Serrote, \% & $46,4^{\mathrm{h}}$ & $46,7^{\mathrm{h}}$ & $45,3^{\mathrm{i}}$ & $48,1^{\mathrm{g}}$ & 2,40 & 0,01 \\
Ponta de agulha, \% & $16,3^{\mathrm{gh}}$ & $15,7^{\mathrm{h}}$ & $16,6^{\mathrm{g}}$ & $14,0^{\mathrm{i}}$ & 5,25 & 0,01 \\
Dianteiro, \% & 37,4 & 37,6 & 38,1 & 37,8 & 2,70 & 0,56
\end{tabular}

${ }^{\mathrm{a}}$ Hereford; ${ }^{\mathrm{b}}$ 3/4 Hereford 1/4 Nelore; ${ }^{\mathrm{c}}$ 5/8 Hereford 3/8 Nelore; ${ }^{\mathrm{d}}$ 3/4 Charolês 1/4 Nelore; ${ }^{\mathrm{e}}$ coeficiente de variação; ${ }^{\mathrm{f}}$ probabilidade; $\mathrm{g}, \mathrm{h,i}$ na linha, média seguidas por letras diferem significativamente entre os grupos genéticos, pelo teste t ao nível de $5 \%$.

Os resultados de similaridade entre os genótipos estudados mostram que os padrões raciais desenvolvidos no melhoramento das raças Charolês, Hereford e Nelore têm mostrado harmonia entre elas. Embora alguns pesquisadores tenham salientado a importância de o melhoramento buscar o aumento do peso de serrote, região onde se localizam os cortes mais valorizados na carcaça bovina (PASCOAL et al., 2011). VAZ et al. (2002), em seu estudo mostraram semelhança entre os genótipos Hereford e $5 / 8 \mathrm{HN}$, para percentagens de dianteiro $(37,4 \%$ para ambos), de ponta de agulha $(14,2$ e $15,1 \%$, respectivamente) e de serrote $(48,5$ e 47,6\%, respectivamente).

No presente estudo, os animais $3 / 4 \mathrm{CN}$ apresentaram o maior percentual de traseiro especial ou corte serrote $(48,1 \%)$, em relação aos outros grupos mestiços $(3 / 4 \mathrm{HN}=46,7 \%$ e $5 / 8 \mathrm{HN}=45,3 \%)$, não diferindo do grupo Hereford $(46,4 \%)$ (Tabela 3 ). O maior percentual de serrote em mestiços de raças continentais é reflexo da seleção que essas raças sofreram para conformação de carcaças (PEROTTO et al., 2000).

$\mathrm{O}$ maior percentual de ponta de agulha (Tabela 3) foi observado nos animais $5 / 8 \mathrm{HN}$, em relação aos $3 / 4 \mathrm{HN}$ e $3 / 4 \mathrm{CN}(\mathrm{P}<0,05)$. Neste estudo, os animais $5 / 8$ eram os que apresentavam maior percentagem de genótipo zebuíno em relação aos demais. Esse resultado pode indicar, para trabalhos futuros, a dessecação da ponta de agulha nos tecidos principais, osso, músculo e gordura, visando estudar qual tecido estaria refletindo em maior desenvolvimento desse corte em animais 5/8 europeu $\mathrm{x}$ zebu. 
$\mathrm{O}$ estado sexual dos animais poderia interferir nos percentuais dos cortes comerciais à medida que o dimorfismo sexual do macho, ativado pelo efeito hormonal androgênico, aumentaria os percentuais de dianteiro em detrimento ao percentual de serrote (BERG \& BUTTERFIELD, 1976). Em função de existirem dúvidas a respeito do desenvolvimento e maturidade dos animais dos diferentes genótipos, no presente trabalho foi estudada a biometria testicular, visando identificar possíveis alterações no desenvolvimento das glândulas sexuais masculinas, que poderiam resultar em diferenças nas produções de hormônios androgênicos e, com isso, maior desenvolvimento de algumas características de carcaça mais expressivas em machos não castrados (Tabela 4).

Tabela 4 - Perímetro escrotal e peso testicular, expressos de forma absoluta, em relação ao peso de fazenda e em relação ao peso de carcaça quente, de bovinos não castrados de diferentes grupos genéticos, abatidos aos quatorze meses

\begin{tabular}{lllllll}
\hline Características & $\mathrm{H}^{\mathrm{a}}$ & $3 / 4 \mathrm{HN}^{\mathrm{b}}$ & $5 / 8 \mathrm{HN}^{\mathrm{c}}$ & $3 / 4 \mathrm{CN}^{\mathrm{d}}$ & $\mathrm{CV}, \%^{\mathrm{e}}$ & $\mathrm{P}^{\mathrm{f}}$ \\
\hline Perímetro escrotal $(\mathrm{PE}), \mathrm{cm}$ & 33,3 & 31,6 & 29,2 & 29,9 & 14,34 & 0,47 \\
PE/peso de fazenda, cm/100 kg & 7,57 & 7,29 & 6,45 & 6,71 & 17,26 & 0,29 \\
PE/peso de carcaça, cm/100 kg & $14,1^{\mathrm{g}}$ & $13,3^{\text {gh }}$ & $11,4^{\mathrm{h}}$ & $12,4^{\text {gh }}$ & 17,15 & 0,04 \\
Peso testicular (PT), g & 514 & 498 & 408 & 420 & 20,59 & 0,59 \\
PT/peso de fazenda, g/100 kg & 1,17 & 1,14 & 0,90 & 0,96 & 29,02 & 0,21 \\
PT/peso de carcaça, g/100 kg & 2,18 & 2,07 & 1,62 & 1,74 & 29,27 & 0,16 \\
\hline
\end{tabular}

${ }^{\mathrm{a}}$ Hereford; ${ }^{\mathrm{b}}$ 3/4 Hereford $1 / 4$ Nelore; ${ }^{\mathrm{c}}$ 5/8 Hereford 3/8 Nelore; ${ }^{\mathrm{d}}$ 3/4 Charolês 1/4 Nelore, e coeficiente de variação; ${ }^{\mathrm{f}}$ probabilidade; ${ }^{\mathrm{g}, \mathrm{h}}$ na linha, média seguidas por letras diferem significativamente entre os grupos genéticos, pelo teste t ao nível de 5\%.

Das variáveis dependentes mostradas na Tabela 4, a única característica que mostrou diferença $(\mathrm{P}<0,05)$ entre os genótipos foi o perímetro escrotal ajustado para $100 \mathrm{~kg}$ do peso de carcaça, que foi maior nos animais Hereford em relação aos $5 / 8 \mathrm{HN}$. O perímetro escrotal variou, sem diferença estatística, de $29,9 \mathrm{~cm}$ nos $3 / 4 \mathrm{CN}$ a $33,3 \mathrm{~cm}$ nos machos Hereford. Menor perímetro escrotal, também chamado de biometria testicular, em animais zebuínos é citado por VALENTIM et al. (2002), quando compararam animais Nelore com mestiços Nelore x raças europeias. DAL-FARRA et al. (2000) correlacionam as diferenças de perímetro escrotal à precocidade das raças europeias em relação às zebuínas.

O monitoramento da biometria testicular em trabalhos que comparam animais abatidos em idade jovem deve-se ao fato de o melhoramento zootécnico buscar a precocidade dos animais, visando reduzir a idade de abate, em vistas à melhoria da qualidade da carne e redução dos custos do sistema de produção pelo aumento da taxa de desfrute. No presente trabalho, parece evidente que o menor perímetro testicular do genótipo com maior percentagem de genótipo zebuíno indica uma maturidade mais tardia, resultante do cruzamento de uma raça dita precoce, no caso a Hereford, com uma raça mais adaptada, porém mais tardia, no caso a Nelore. No entanto, as características de precocidade de terminação associadas à deposição de gordura, possuem alta heterose em cruzamentos de genótipos zebuínos e europeus (VAZ \& RESTLE, 2001), fato que pode ter compensado um possível menor acabamento dos animais que apresentassem uma maturidade mais tardia pelo maior grau de sangue zebuíno.

\section{CONCLUSÕES}

Não há diferença nos pesos de carcaça quente e carcaça fria, rendimentos de carcaça quente e de carcaça fria e na quebra ao resfriamento das carcaças entre machos Hereford, mestiços Hereford $\mathrm{x}$ Nelore e mestiços Charolês x Nelore, implicando que esses genótipos são adequados para o atual sistema de comercialização brasileiro, que não diferencia composição dos tecidos da carcaça e percentagens dos cortes primários.

Considerando-se a composição da carcaça, animais mestiços Charolês apresentam melhor conformação e maior área de Longissimus dorsi do que novilhos mestiços Hereford. Estes últimos e o Hereford puro, em idade jovem, possuem carcaças com maior gordura de cobertura e percentagem de ponta de agulha que os mestiços Charolês.

Se avaliada a biometria testicular, os animais 3/8 Nelore indicam ser mais tardios que os machos Hereford puros, porém a heterozigose presente no genótipo pode melhorar o acabamento desses animais. 


\section{REFERÊNCIAS}

ARANGO, J.A.; CUNDIFF, L.V.; VAN VLECK, L.D. Comparisons of Angus, Charolais, Galloway, Hereford, Longhorn, Nellore, Piedmontese, Salers, and Shorthorn breeds for weight, weight adjusted for condition score, height, and condition score of cows. Journal of Animal Science, v.82, n.1, p.74-84, 2004

BAKER, F. Running a small beef herd. 3.ed. Collingwood: Landlinks Press, 2008.

BARBER, K.A.; WILSON, L.L.; ZIEGLER, J.H.; LEVAN, P.J.; WATKINS, J.L. Charolais and Angus steers slaughtered at equal percentages of mature cow weight. I. effects of slaughter weight and diet energy density on carcass traits. Journal of Animal Science, v.52, n.1, p.218-231, 1981.

BERG, R.T.; BUTTERFIELD, R.M. New concepts of cattle growth. New York: Halsted Press, 1976.

BIDNER, T.D.; WYATT, W.E.; HUMES, P.E.; FRANKE, D.E.; BLOUIN, D.C. Influence of Brahmanderivative breeds and Angus on carcass traits, physical composition, and palatability. Journal of Animal Science, v.80, n.9, p.2126-2133, 2002.

DAL-FARRA, R.A.; ROSO, V.M.; KILPP, D.V. Fatores de correção do perímetro escrotal para efeitos de idade, peso e heterozigose individual em touros mestiços Angus x Nelore. Revista Brasileira de Zootecnia, v.29, n.6, p.2002-2007, 2000 (suplemento 1).

HANKINS, O.G.; HOWE, P.E. Estimation of the composition of beef carcasses and cuts. Washington. D.C.: USDA, 1946. (Technical Bulletin - USDA, 926).

IGARASI, M.S.; ARRIGONI, M.B.; SOUZA, A.A.; SILVEIRA, C.L.M.; OLIVEIRA, H.N. Desempenho de bovinos jovens alimentados com dietas contendo grão úmido de milho ou sorgo. Revista Brasileira de Zootecnia, v.37, n.3, p.513-519, 2008.

ÍTAVO, L.C.V.; DIAS, A.M.; ÍTAVO, C.C.B.F.; EUCLIDES FILHO, K.; MORAIS, M.G.; SILVA F.F.; GOMES, R.C.; SILVA, J.P.B. Desempenho produtivo, características de carcaça e avaliação econômica de bovinos cruzados, castrados e não-castrados, terminados em pastagens de Brachiaria decumbens. Arquivo Brasileiro de Medicina Veterinária e Zootecnia, v.60, n.5, p.1157-1165, 2008.

KOGER, M. Effective crossbreeding systems utilizing zebu cattle. Journal of Animal Science, v.50, n.6, p.1213-1220, 1980.

MÜLLER, L. Normas para avaliação de carcaças e concurso de carcaças de novilhos. Santa Maria: Imprensa Universitária, 1987, 31p.

NATIONAL RESEARCH COUNCIL - NRC. Nutrients requeriments of beef cattle. 7. ed. Washington, D. C., 1996.
OLIVEIRA, E.A. de; SAMPAIO, A.M.M.; FERNANDES, A.R.M.; HENRIQUE, W.; OLIVEIRA, R.V.; RIBEIRO, G.M. Desempenho e características de carcaça de tourinhos Nelore e Canchim terminados em confinamento recebendo dietas com cana-de-açúcar e dois níveis de concentrado. Revista Brasileira de Zootecnia, v.38, n.12, p.2465-2472, 2009.

PACHECO, P.S.; SILVA, J.H.S.; RESTLE, J.; ARBOITTE, M.Z.; BRONDANI, I.L.; FILHO, D.C.A.; FREITAS, A.K. Características quantitativas da carcaça de novilhos jovens e superjovens de diferentes grupos genéticos. Revista Brasileira de Zootecnia, v.34, n.5, p.1666-1677, 2005.

PEROTTO, D.; MOLETTA, J.L.; CUBAS, A.C. Características quantitativas da carcaça de bovinos charolês, caracu e cruzamentos recíprocos terminados em confinamento. Revista Brasileira de Zootecnia, v.29, n.1, p.117-124, 2000

PURCHAS, R.W.; BURNHAM, D.L.; MORRIS, S.T. Effects of growth potential and growth path on tenderness of beef longissimus muscle from bulls and steers. Journal of Animal Science, v.80, n.12, p.3211-3221, 2002.

SAMPAIO, A.M.M.; BRITO, R.M.; VIEIRA, P.F.; TOSI, H. Efeito da suplementação protéica sobre crescimento, terminação e viabilidade econômica de bezerros mestiços canchim confinados pós-desmama. Revista Brasileira de Zootecnia, v.27, n.4, p.823-831, 1998.

SANTOS, E.D.G.; PAULINO, M.F.; LANA, R.P.; FILHO, S.C.V.; QUEIROZ, D.S. Influência da suplementação com concentrados nas características de carcaça de bovinos F1 Limousin - Nelore, não-castrados, durante a seca, em pastagens de Brachiaria decumbens. Revista Brasileira de Zootecnia, v.31, n.4, p.1823-1832, 2002.

SHERBECK, J.A.; TATUM. J.D.; FIELD, T.G.; MORGAN, J.B.; SMITH, G.C. Feedlot performance, carcass traits, and palatability traits of Hereford and Brahman x Brahman steers. Journal of Animal Science, v.73, n.12, p.3613-3620, 1995.

TORAL, F.L.B.; ROSO, V.M.; ARAÚJO, C.V.; REIS FILHO, J.C. Genetic parameters and response to selection for post-weaning weight gain, visual scores and carcass traits in Hereford and Hereford $\mathrm{X}$ Nellore cattle. Livestock Science, v.137, n.1-3, p.231-237, 2011.

VALENTIM, R.; ARRUDA; R.P.; BARNABE, R.C.; ALENCAR, M.M. Biometria testicular de touros Nelore (Bos taurus indicus) e touros cruzados Nelore-europeu (Bos taurus indicus x Bos taurus taurus) aos 20 e 24 meses de idade. Brazilian Journal Veterinary Research and Animal Science, v.39, n.3, p.113-120, 2002.

VAZ, F.N.; RESTLE, J. Efeito de raça e heterose para características de carcaça de novilhos da primeira geração de cruzamento entre Charolês e Nelore. Revista Brasileira de Zootecnia, v.30, n.2, p.409-416, 2001.

VAZ, F.N.; RESTLE, J.; PACHECO, P.S.; FREITAS, A.K.; PEIXOTO, L.A.O.; CARRILHO, C.O. 
Características de carcaça e da carne de novilhos fêmeas de dois anos. Revista Brasileira de Zootecnia, superprecoces de três grupos genéticos, gerados por v.31, n.5, p.1973-1982, 2002.

Protocolado em: 14 mar. 2012 Aceito em: 10 set. 2012. 